\title{
AN EXPERIMENTAL INVESTIGATION ON PARTIAL REPLACEMENT OF SAND BY CERAMIC GRAINS IN COCONUT SHELL CONCRETE
}

\author{
S. Prakash Chandar, K. Gunasekaran, V. Kalpana Priya* \\ and N. Ganapathyramasamy \\ Department of Civil Engineering, SRM IST, Kattankulathur-603203, Tamil Nadu, India \\ *E-mail: kalpanacivilian@gmail.com
}

\begin{abstract}
In this work to find some alternative replacement for fine aggregate to save natural resource. The fine aggregate is partially replaced by the ceramic waste in various portion $(10 \%, 20 \%, 30 \%, 40 \%$, and $50 \%)$ in coconut shell concrete. The sources of natural sand and aggregate are reducing day by day and these are becoming consequently costlier as their demand also increases every day. For example, ceramic wastes are waste products which are directly released into the environment and can cause pollution, so using such materials as a substitute in fine aggregate can also reduce the disposal problems associated with these materials. In this study we will be finding out the compressive strength test, flexural strength, split tensile strength and failure analysis of RCC beams after 3, 7 and 28 days on replacement of river sand by the ceramic waste in the coconut shell concrete.

Keywords: Coconut shell, Ceramic waste, Compression strength, Split tensile strength, Flexural strength

(C) RASĀYAN. All rights reserved

\section{INTRODUCTION}

Concrete is developed by the mixer of materials like cement, fine aggregate, coarse aggregate and water in some appropriate proportions. About 7.23 billion tons of concrete are produced every year and the rate of producing the concrete is increasing every day due to the high growth of construction development and construction demand around the world. Concrete production is affected by the demand in cement, fine aggregate, coarse aggregate, water, and other admixtures. Due to increasing demand in natural aggregates, the use of conventional aggregates are made uneconomical. Replacement of conventional blue metal aggregate with alternatives generated from waste in the concrete matrix adds to effective waste management thereby adding to the integrity towards sustainability. India with 1.78 million hectares for coconut production is the third largest producer of coconut in this planet. However, coconut shell is the waste produced from the coconut which also causes the main pollution problem to the nation, which involves annual productivity of approximately 3.18 million tons. This paper investigates the utilization of coconut shell in crushed and granular form replacing the coarse aggregate in the concrete matrix. The effect of strength of concrete is monitored with the addition of adding ceramic waste grains as fine aggregate and effectively reutilizes the waste materials.
\end{abstract}

\section{EXPERIMENTAL}

\section{Material Used}

Cement

OPC of grade 53 conforming to IS 8112-1989 was used. This cement exhibits greater strength and durability to the building structures due to its crystalline structure and orientation of particle size.

\section{Fine Aggregate}

In this study river sand is used as fine aggregate along the concrete matrix. The properties of sand were determined by conducting test per IS: 2386 (Part - I). The specific gravity for sand is 2.7 and it indicates that the sand conforms to Zone II of IS 383-1970.

Rasayan J. Chem., 12(2), 659-665(2019)

http://dx.doi.org/10.31788/RJC.2019.1225227

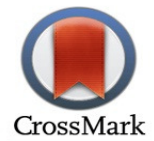




\section{Coarse Aggregate}

The coarse aggregate size is maximum of $12.5 \mathrm{~mm}$ was used for this study and the properties were determined by conducting tests as per IS: 2386 (Part - III). The specific gravity, aggregate crushing value and the impact value is found out to be $2.77,18.90$ and 30.23 respectively.

\section{Coconut Shell}

The new coconut shells were collected from the industries and they were well cleaned. The cleaned coconut shell is crushed by crusher, which was developed in SRM University specifically for crushing the material. The crushed material was flaky and the length was not more than $12.5 \mathrm{~mm}$. The texture of the coconut shell was rough on one face and smooth on other faces. The coconut shell was immersed into water for $24 \mathrm{hrs}$ and then it's converted into SSD condition.

\section{Design Mix}

The constituents of the concrete mix were proportioned for an M-25 grade achieved through IS 10262:2009 coining to a ratio of 1:2.22:3.66 for control concrete and 1:1.47:0.64 for coconut shell with a $\mathrm{W} / \mathrm{C}$ ratio of 0.55 and 0.42 respectively.

\section{Casting of Specimen}

The tests are conducted on specimens such as compressive strength, flexural strength and split tensile strength were carried out to determine the characteristics of conventional concrete and concrete with ceramic grains replacements along with coconut shell particles. Concrete cubes, cylinders and beams were cast pertaining to the design mix with mould dimensions of $100 \times 100 \times 100 \mathrm{~mm}, 100 \times 200 \mathrm{~mm}$ in diameter, and $1500 \times 150 \times 230 \mathrm{~mm}$ respectively.

\section{Curing of Specimen}

The conventional concrete specimens including the cube, cylinder and beam, were cured by normal ponding technique for 28 days to achieve the characteristic strength and the concrete specimen with the replacement of ceramic grains were subjected to an aerated curing technique for monitoring the behavior of the concrete under test loads.

\section{Testing of Specimen}

\section{Compressive Strength Test}

The conventional concrete specimen and the specimen with replacement are tested under compressive loads and the results are noted at $3^{\text {rd }}, 7^{\text {th }}$ and $28^{\text {th }}$ day. The compressive strength of specimens was noted as shown in Fig.-1.

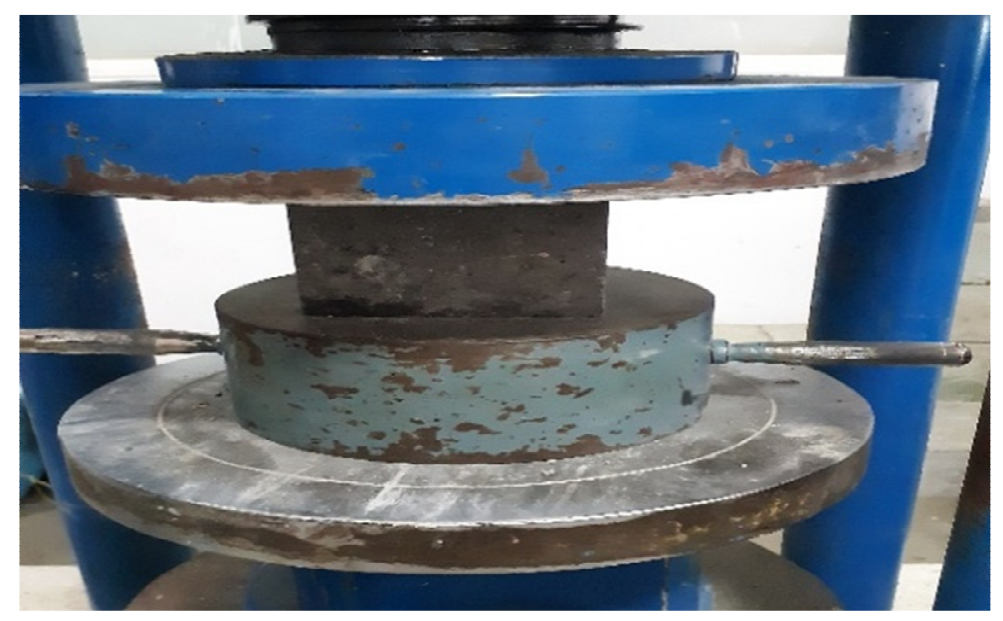

Fig.-1: Compressive Strength Test on a Specimen 
RASĀYAN J. Chem.

Vol. 12 | No. 2 |659 - 665| April - June | 2019

Table-1: Results Show the Compressive Strength on Cubes

\begin{tabular}{c|c|c|c|c|c}
\hline \multirow{2}{*}{ Type } & $\begin{array}{c}\text { Replacement of Ceremic } \\
\text { Waste in }(\%)\end{array}$ & \multirow{2}{*}{ Density Kg/m } & \multicolumn{3}{|c}{ Compressive Strength $/ \mathrm{mm}^{2}$} \\
\cline { 4 - 6 } & $0 \%$ & 2480 & 16.74 & 19.82 & 27.89 \\
\hline CC & $0 \%$ & 1992 & 12.5 & 18.2 & 28.41 \\
\hline CSC & $10 \%$ & 2014 & 12.7 & 19.8 & 27.12 \\
\hline \multirow{4}{*}{ CSC-CW } & $20 \%$ & 2039 & 12.9 & 20.6 & 26.23 \\
\cline { 2 - 6 } & $30 \%$ & 2062 & 12.6 & 19.4 & 25.7 \\
\cline { 2 - 6 } & $40 \%$ & 2083 & 12.2 & 18.2 & 25.12 \\
\cline { 2 - 6 } & $50 \%$ & 2104 & 11.5 & 16.7 & 24.6 \\
\hline
\end{tabular}

\section{COMPRESSIVE STRENGTH N/mm2}

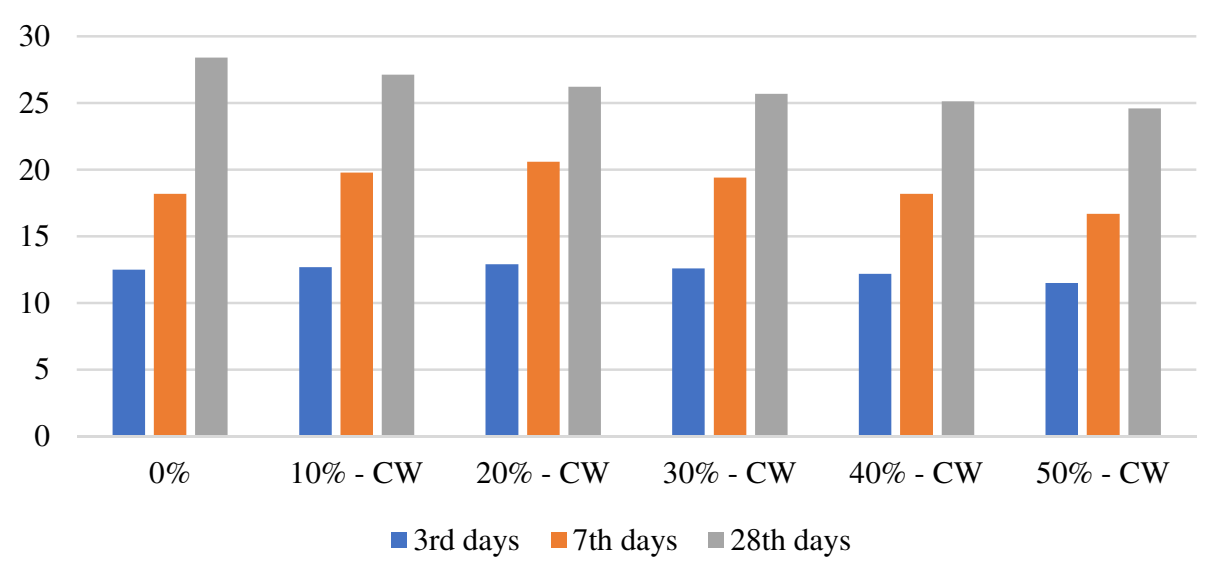

Fig.-2: Compressive Strength on Ceramic replaced Concrete

\section{Split Tensile Strength Test}

The conventional concrete specimen and the specimen with replacements are subjected to tensile loads and the load applied, the behavior of concrete and point of failure is documented as shown in Fig.-3. The splitting tensile strength is calculated using the formula, $\mathrm{F} \alpha=2 \mathrm{P} / \pi \mathrm{dl}$. Here, $\mathrm{P}$-Load in kilo newtons applied, 1 - vertical length of the specimen, $\mathrm{d}$ - diameter of the specimen.

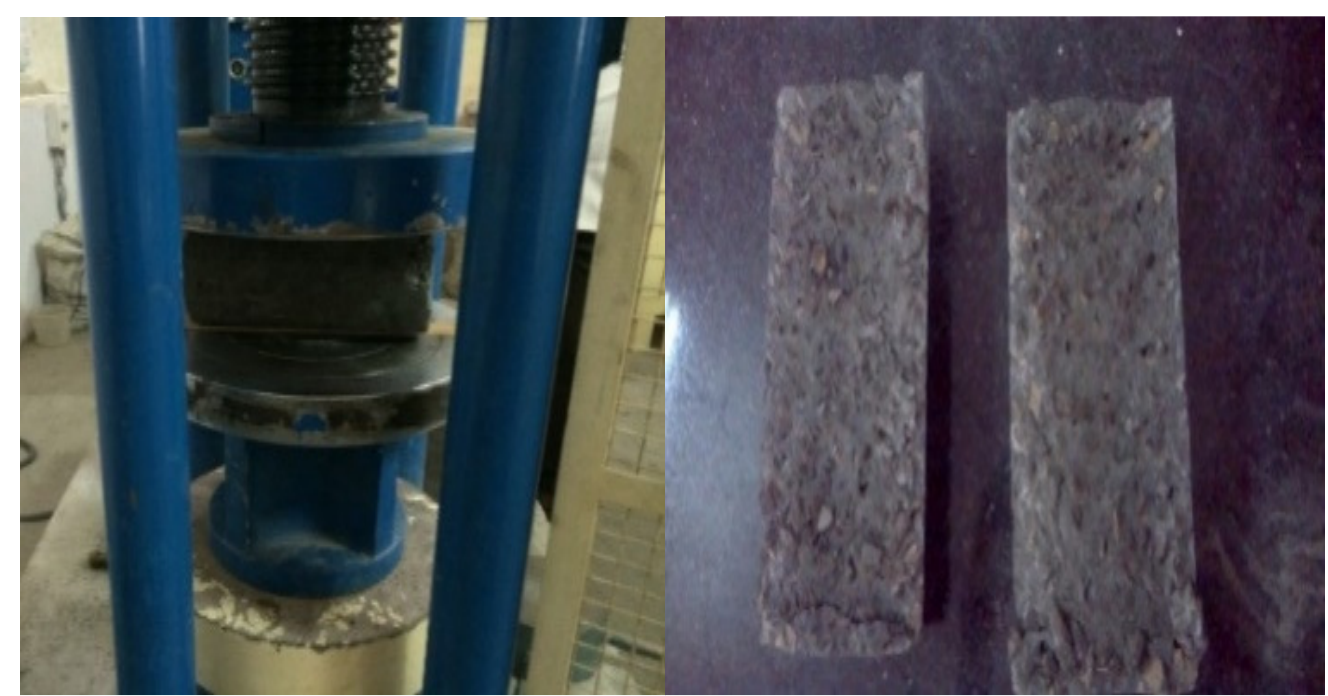

Fig.-3: Split Tensile Strength Test on a Specimen 
Vol. 12 | No. 2 |659 - 665| April - June | 2019

Table-2: Results Show the Split Tensile Strength on a Specimen

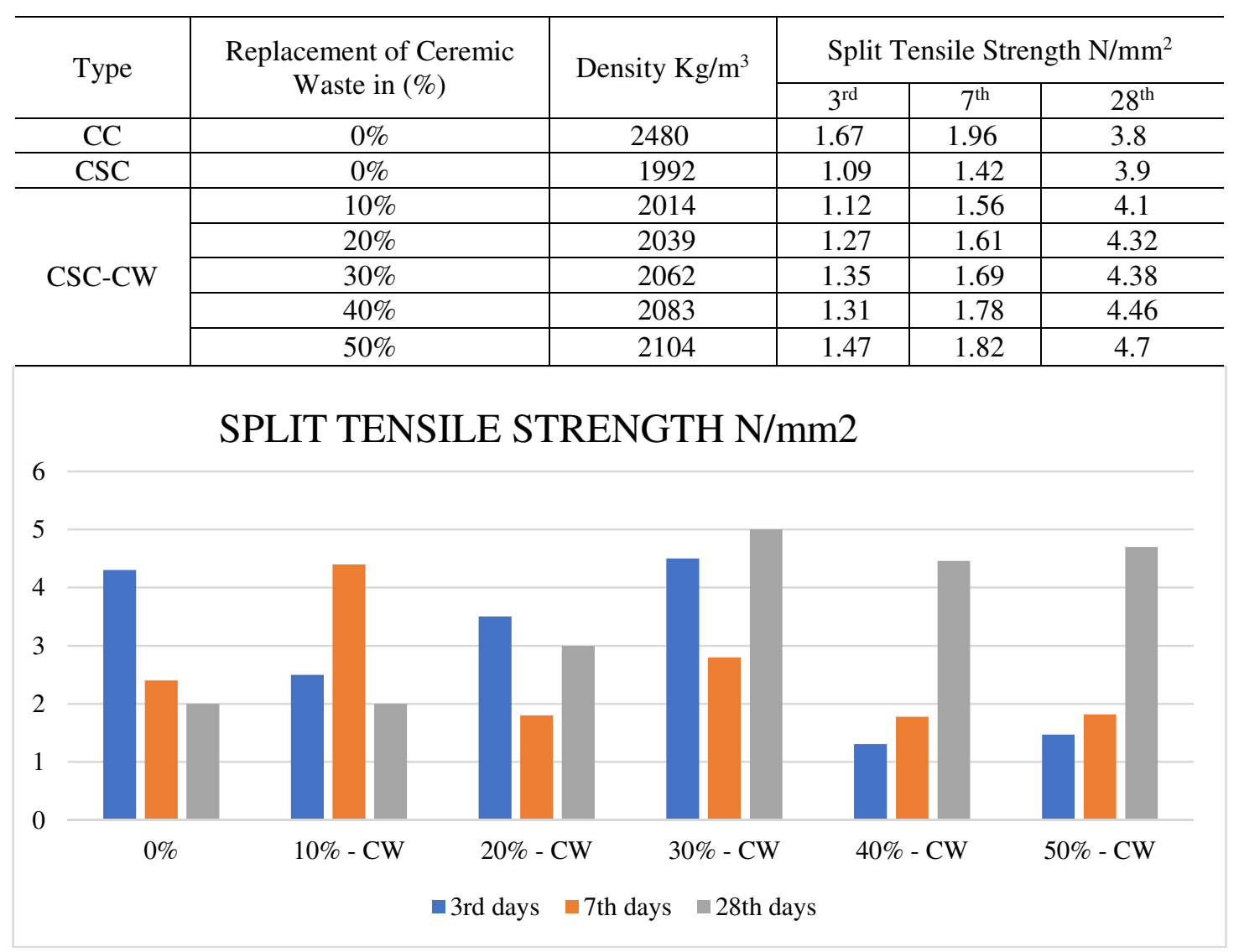

Fig.-4: Split Tensile Strength on Ceramic replaced Concrete

\section{Flexural Strength Test Results}

The deflection is determined by placing a deflectometer at the middle point of the specimen and the load is gradually increased. The yield load is identified and further increased at fixed intervals. The load at which the beam fails is recorded and the load-deflection curve is plotted to find the curve.

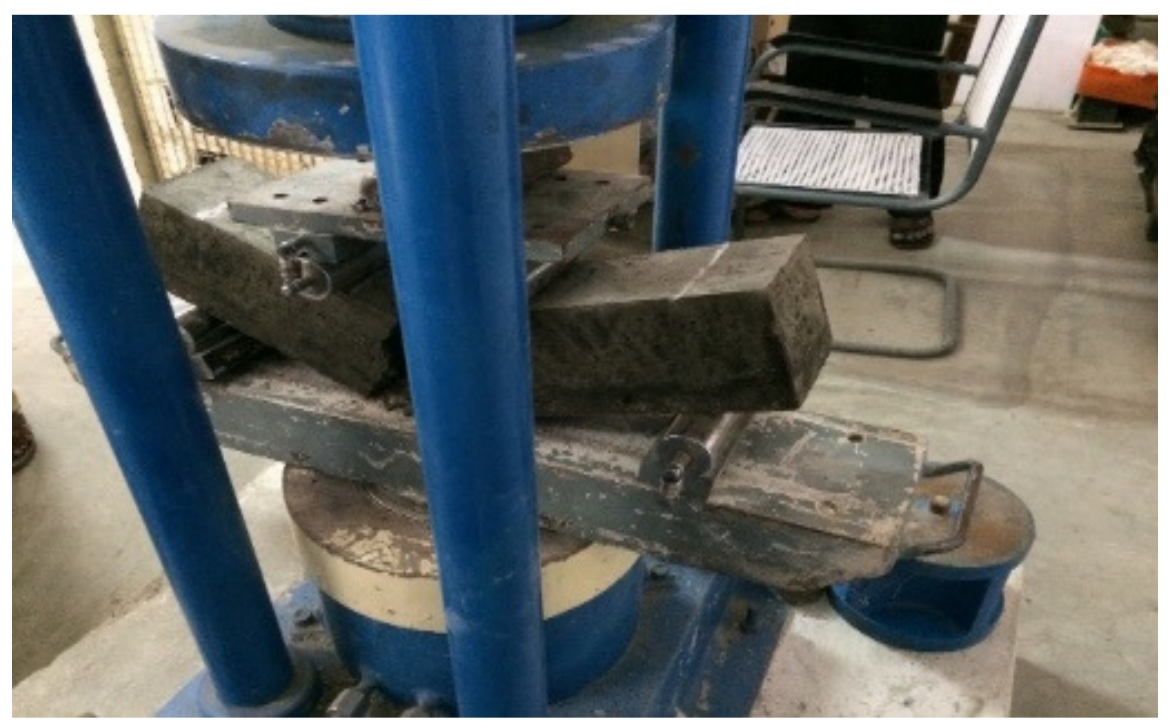

Fig.-5: Flexural Strength Test on a Specimen 
Vol. 12 | No. 2 |659 - 665| April - June | 2019

Table-4: Results Show the Flexural Strength on Specimens

\begin{tabular}{c|c|c|c|c|c}
\hline \multirow{3}{*}{ Type } & \multirow{2}{*}{$\begin{array}{c}\text { Replacement of } \\
\text { Ceremic Waste in (\%) }\end{array}$} & \multirow{2}{*}{$\begin{array}{c}\text { Density } \\
\text { Kg/m }\end{array}$} & \multicolumn{3}{|c}{ Flexural Strength } \\
\cline { 4 - 6 } & & & $3^{\text {rd }}$ & $7^{\text {th }}$ & $28^{\text {th }}$ \\
\hline CC & $0 \%$ & 2480 & 1.94 & 3.6 & 4.89 \\
\hline CSC & $0 \%$ & 1992 & 1.68 & 2.77 & 4.79 \\
\hline \multirow{4}{*}{ CSC-CW } & $10 \%$ & 2014 & 1.76 & 2.95 & 4.81 \\
\cline { 2 - 6 } & $20 \%$ & 2039 & 1.81 & 3.2 & 4.93 \\
\cline { 2 - 5 } & $30 \%$ & 2062 & 1.80 & 3.4 & 4.97 \\
\cline { 2 - 5 } & $40 \%$ & 2083 & 1.82 & 3.7 & 4.9 \\
\cline { 2 - 5 } & $50 \%$ & 2104 & 1.86 & 3.9 & 5.21 \\
\hline
\end{tabular}

\section{FLEXURAL STRENGTH N/mm2}

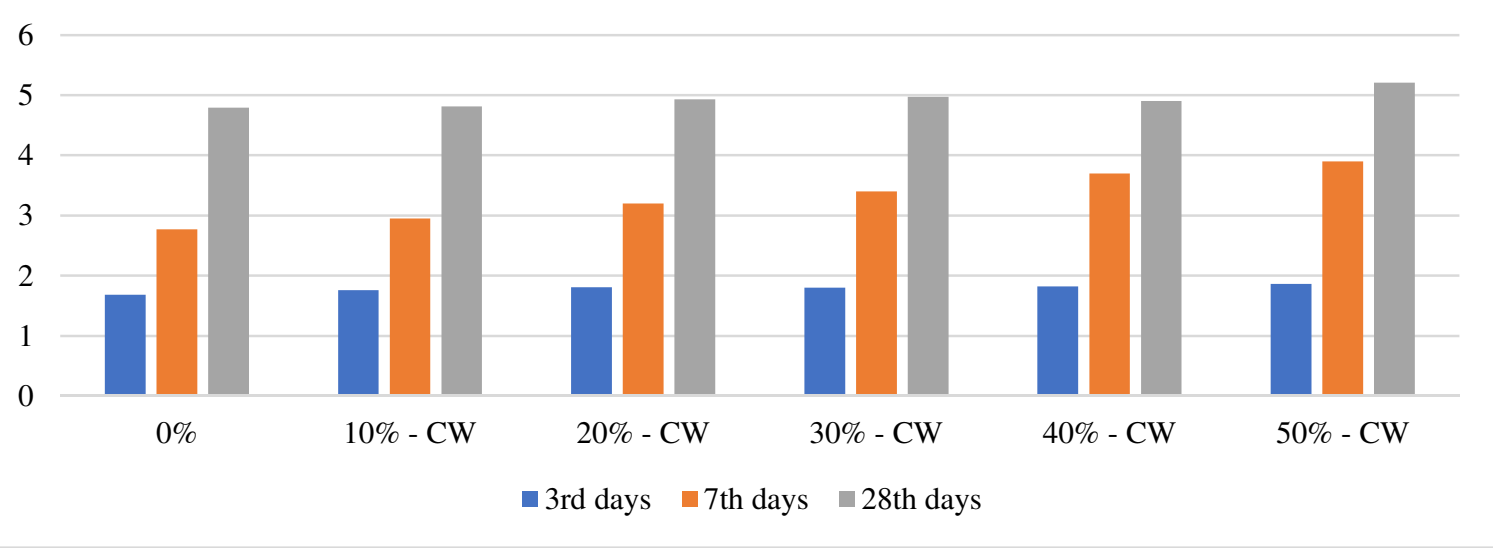

Fig.-6: Flexural Strength on Ceramic replaced Concrete

\section{Failure Analysis of RCC Beam}

Reinforced cement concrete beam testing is the method to know the behavior of concrete. Deflection in RCC beam will determine the failure at maximum load. It will be achieved by testing the beam with twopoint loading. Three deflectometer is placed at the bottom of the beam to know the change in dimension of the specimen which bends under loading. The RCC beam size is $1500 \mathrm{~mm} \times 150 \mathrm{~mm} \times 230 \mathrm{~mm}$. The reinforcements are $10 \mathrm{~mm}$ bars as the main bar and $6 \mathrm{~mm}$ bars as stirrups at a spacing of $150 \mathrm{~mm} \mathrm{c} / \mathrm{c}$. The test results of the RCC beam with deflections are discussed in the following table.

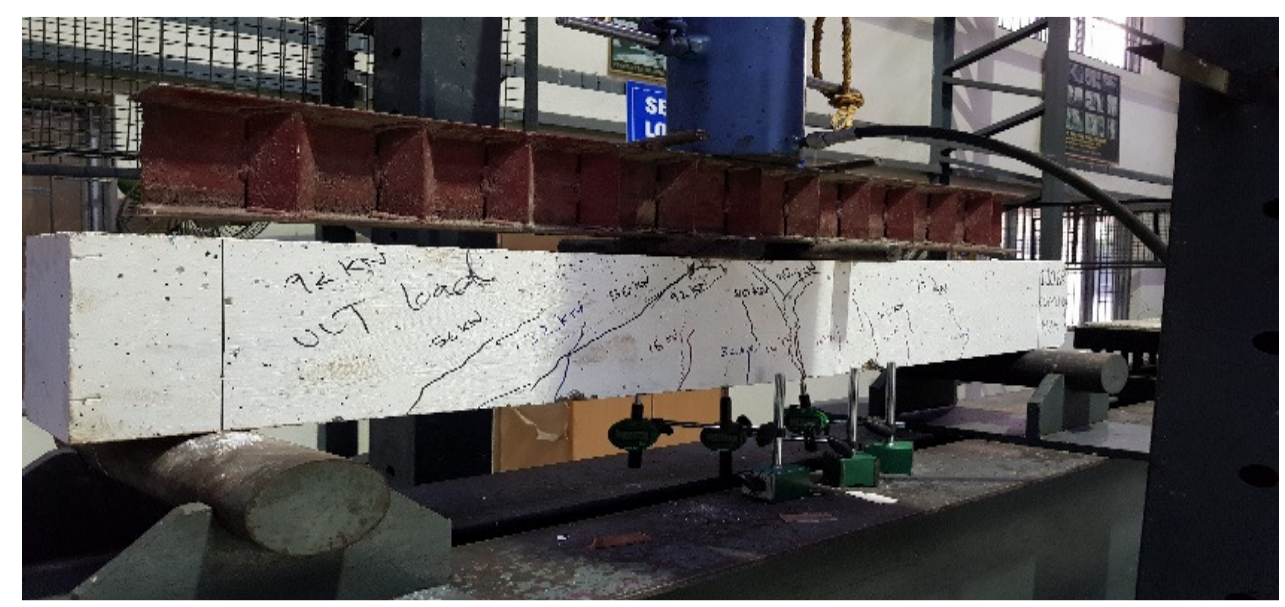

Fig.-7: Load Deflection Test on RCC Beams 
Vol. 12 | No. 2 |659-665| April - June | 2019

Table-5: Load - Deflection Values of Reinforced Beams

\begin{tabular}{c|c|c|c}
\hline Type & $\begin{array}{c}\text { Replacement of Ceremic } \\
\text { Waste in }(\%)\end{array}$ & $\begin{array}{c}\text { Breaking Load } \\
\text { (Tons) }\end{array}$ & $\begin{array}{c}\text { Maximum Deflection at Centre } \\
(\mathrm{mm})\end{array}$ \\
\hline CC & $0 \%$ & 12.9 & 10.06 \\
\hline \multirow{3}{*}{ CSC- } & $10 \%$ & 12.38 & 10.30 \\
\cline { 2 - 4 } CW & $20 \%$ & 11.27 & 10.52 \\
\cline { 2 - 4 } & $30 \%$ & 10.41 & 11.76 \\
\hline
\end{tabular}

\section{LOAD DEFLECTION VALUES OF REINFORCED BEAMS}

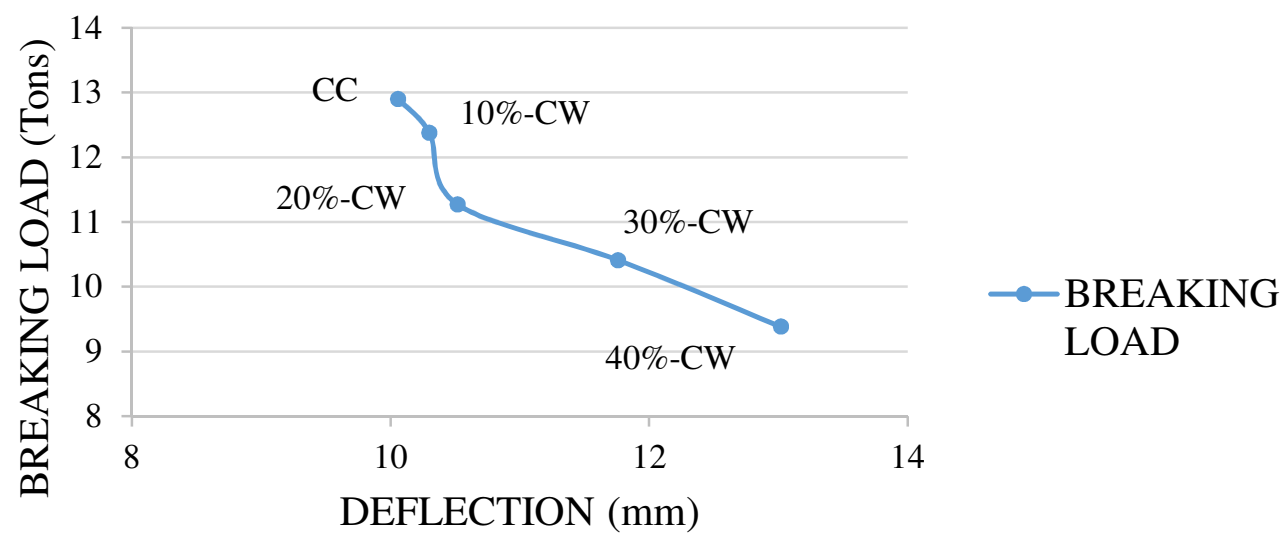

Fig.-8: Load-Deflection Values for Reinforced Beams

\section{CONCLUSION}

- The replacement of ceramic waste can be optimized as a fine aggregate in the concrete.

- Strength properties were decreased in comparison to conventional concrete at the replacement of $10 \%, 20 \%, 30 \%, 40 \%$, and $50 \%$,

- Replacement is done up to $50 \%$ but up to $40 \%$ replacement is more suitable for replacement of fine aggregate in the production of concrete.

- While replacing river sand by ceramic waste can possible to save natural resources.

- By the usage of ceramic waste, it reduces the cost of construction projects.

\section{ACKNOWLEDGMENT}

This study was supported and grant of permission to use the lab facilities was given by SRM Institute of Science and Technology, Chennai.

\section{REFERENCE}

1. S. Prakash Chandar, K. Gunasekaran, N. Sai Sandeep et al., Rasayan Journal of Chemistry, 10, 528(2017), DOI: 10.7324/RJC.2017.1021636.

2. S. Prakash Chandar, K. Gunasekaran, K. Prasanth et al., Rasayan Journal of Chemistry, 11, 702(2018), DOI: 10.31788/RJC.2018.1123003.

3. R. Ramasubramani, K. S. Sathyanarayanan, et al., Rasayan Journal of Chemistry, 9, 706(2016).

4. K. Divya Krishnan, P.T. Ravichandran, V. K. Gandhimathi, Rasayan Journal of Chemistry, 10, 600(2017), DOI:10.7324/RJC.2017.1021677.

5. L. Krishnaraj, R. Suba Lakshmi, P. T. Ravichandran, Rasayan Journal of Chemistry, 10, 592(2017), DOI: $10.7324 /$ RJC.2017.1021670. 
RASĀYAN J. Chem.

Vol. 12 | No. 2 |659 - 665| April - June | 2019

6. K. Gunasekaran, R. Ramasubramani, R. Annadurai, S. Prakash Chandar, International journal of Materials and Design, 57,374(2014), DOI: 10.1016/j.matdes.2013.12.058.

7. A. Manimaran, Seenu Santhosh, P. T. Ravichandran, Rasayan Journal of Chemistry, 11, 401(2018), DOI: $10.7324 /$ RJC.2018.1112044.

8. K. Gunasekaran, P. S.Kumar, M. Lakshmipathy, International Journal of Construction and Building Materials, 25, 92(2011), DOI: 10.1016/j.conbuildmat.2010.06.053.

9. K. Divya Krishnan, Mani Deepika, P. T. Ravichandran et al., Indian Journal of Science and Technology, 9, 1(2016), DOI: 10.17485/ijst/2016/v9i23/95980.

10. L. Krishnaraj, Yeddula Bharath Simha Reddy et al., Rasayan journal of Chemistry, 10, 423(2017), DOI: $10.7324 /$ RJC.2017.1021682

[RJC-5227/2019] 